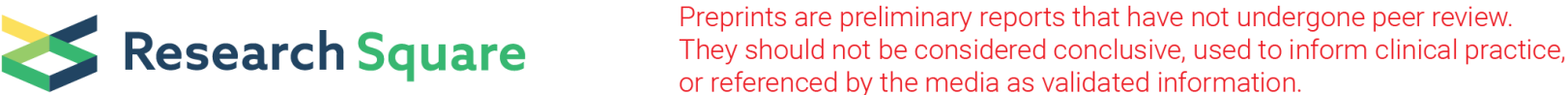

\section{Long Term Spatio-Temporal Trends In Aerosol Optical Depth And Its Relationship With Enhanced Vegetation Index And Meteorological Parameters Over South Asia}

\section{Salman Tariq ( $\nabla$ salman.spsc@pu.edu.pk)}

University of the Punjab

\section{Fazzal Qayyum}

University of the Punjab Quaid-i-Azam Campus: University of the Punjab

\section{Zia Ul-Haq}

University of the Punjab Quaid-i-Azam Campus: University of the Punjab

\section{Usman Mehmood}

University of the Punjab Quaid-i-Azam Campus: University of the Punjab

\section{Research Article}

Keywords: Aerosols, Meteorological parameters, Remote sensing, South Asia

Posted Date: September 14th, 2021

DOl: https://doi.org/10.21203/rs.3.rs-774811/v1

License: (c) (i) This work is licensed under a Creative Commons Attribution 4.0 International License.

Read Full License 


\section{Abstract}

Satellite-based Aerosol optical depth (AOD) is columnar light extinction by aerosol absorption and scattering and has become the most important variable for the assessment of the spatiotemporal distribution of aerosols at a regional and global level. In this paper, we have used AOD observations from multi-angle imaging spectroradiometer (MISR), moderate resolution imaging spectroradiometer (MODIS) and sea viewing wide field-of-view Sensor (SeaWiFS). We have observed the association of AOD with enhanced vegetation index (EVI) and meteorological variables (temperature (TEMP), WS and relative humidity $(\mathrm{RH})$ ). The findings show that AOD in eastern Pakistan is higher than in the western Pakistan due to increase in population density and biomass burning. Mean annual peak AOD ( $\triangle 0.7)$ has been observed over the IGB region because of the significant increase in economical, industrial and agricultural activities. The highest seasonal mean AOD (0.8) has been seen over Bihar, India during the winter season. However, the mean AOD over eastern Pakistan is maximum in both monsoon and post-monsoon season but relatively low in pre-monsoon and winter. The higher mean AOD anomaly value is found to be 0.2 over eastern Pakistan and western India. In northeastern Pakistan and central India, AOD and RH are positively correlated ( $R$ 凶0.54) while negatively correlated over southwestern Pakistan. AOD is negatively correlated $(R=\sim-0.3)$ with EVI over northeastern and southeastern Pakistan. The correlation coefficient $(R)$ obtained among Aqua and Terra AOD is 0.97 over south Asia. The satellite observations of Aqua-AOD was also compared with SeaWiFS and MISR AOD.

\section{Introduction}

Atmospheric aerosols are solid or liquid particles ranging from $(0.001-100 \mu \mathrm{m})$, emitting from both anthropogenic and natural sources, suspended in the earth's atmosphere and have impacts on the ecosystem, air quality, atmospheric chemistry and visibility (Streets et al., 2009; Han et al., 2013). Aerosols play a key role in the destruction of health and climate system (Tariq et al., 2018).

Non-uniformity in their sources and a short life span of few days in the atmosphere limits the understanding of the spatiotemporal distribution of aerosols (Logan et al., 2013). For a better understanding of aerosol distribution in the atmosphere at high spectral and temporal resolutions, an insitu observational instrument aerosol robotic network (AERONET) was used globally for continuous observations of aerosol properties (Alam et al., 2018). However, these in-situ observations provide accurate information on aerosols but are limited over regional and global scales (Tariq and Ali, 2015). To better address this spatial limitation problem, satellite datasets have been used to monitor the spatiotemporal distribution of aerosols at territorial and global scale (Remer et al., 2005; Tariq et al., 2018; Nichol et al., 2016).

In recent years, aerosols emission from both human and natural activities have reduced the air quality of many Asian cities. Particulates of complex mixtures of light scattering and absorbing are found in Asian aerosols. Brown carbon, iron oxide and soot or black carbon are three main light-absorbing species while vehicular emissions, biomass burning and industrial sources are the main light-scattering aerosols. 
Prasad and Singh, (2007) have found an increasing Aerosol Optical Depth (AOD) trend over northern India using MISR, MODIS and AERONET data from 2001 to 2005. Tariq et al. (2018) analyzed AOD variations over Pakistan and described the rising trends in the mean annual AOD over the southern and northeastern region from 2000 to 2014.

The rapid increase in urbanization, industrialization, population density and anthropogenic activities have been experienced in mega-cities of South Asia in recent years. Spatiotemporal distribution of aerosols in south Asia is poorly understood because of limited monitoring networks and satellite observation at high resolution (Guo et al., 2011). The main aim of this work is to observe the spatiotemporal distributions of aerosols over South Asia using datasets of 18 years. For this purpose, we have analyzed the association of Aqua-AOD with enhanced vegetation index (EVI) and meteorological variables during the period September 2002 to December 2020. Furthermore, Aqua-MODIS data has also been compared with TerraMODIS, SeaWiFS and MISR.

\section{Material And Methods}

\subsection{Study area}

The Rapid increase in population and economy of South Asia in recent years have caused a significant increase in energy utilization, which has drastically increased AOD over south Asian countries.

Afghanistan, Nepal, Maldives, Bhutan, Sri Lanka, India, Bangladesh and Pakistan are the main countries of South Asia (Figure 1). Geographically, it consists of valleys, rain forests, deserts, glaciers and grasslands. The climate of South Asia varies from area to area, from temperate in the north to tropical monsoon in the south. The northern part of the Indo-Gangetic belt (IGB) has high temperatures in the summer season and relatively low in winter. It can be divided into five main regions: the Karakoram and Himalayan mountains in the north, the southern lowlands, the Baluchistan Plateau, peninsular India and the island realm.

\subsection{Instrumentation}

\subsubsection{MODIS}

MODIS sensor aboard the Aqua and Terra satellites have provided daily global measurement of aerosols with a swath width of $\sim 2330 \mathrm{~km}$ and creating geophysical datasets. Aqua and Terra are polar-orbiting satellites at an altitude nearly equal to $700 \mathrm{~km}$. MODIS sensor has 36 spectral bands $(0.41$ to $14 \mu \mathrm{m})$ at variable spatial resolutions $(250 \mathrm{~m}, 500 \mathrm{~m}$ and $1 \mathrm{~km})$ and temporal resolution of $1-2$ days. In this study, we have used Aqua-MODIS monthly (MYD08_M3 v6.1) product at $1^{\circ} \times 1^{\circ}$ spatial resolution and monthly mean EVI product (MYD13C2 v006) during the period September 2002-December 2020 acquired from Giovanni (http://giovanni.gsfc.nasa.gov).

\subsubsection{MISR}


MISR onboard Terra satellite was launched by NASA (National Aeronautics Space and Administration) in 1999 at an elevation of $705 \mathrm{~km}$ and has a temporal resolution of 16 days as well as the spatial resolution of $250 \mathrm{~m}, 275 \mathrm{~m}$ and $1 \mathrm{~km}$. It is intended to monitor all patterns and kinds of vaporized particles created from anthropogenic and natural activities. We have used MISR-AOD (MIL3MAE v4) data product at $0.5^{\circ} \times 0.5^{\circ}$ spatial resolution during the period September 2002-December 2020 acquired from Giovanni (http://giovanni.gsfc.nasa.gov). Kahn et al. (2010) reported detailed data on MISR instrumentation, recovery algorithms and methodology.

\subsubsection{SeaWiFS}

SeaWiFS onboard Sea Star satellite was first introduced in 1997 and has a temporal resolution of 2 days with a swath width of $1,502 \mathrm{~km}$. It can measure the small contribution of the ocean to the reflected solar radiance at top of the atmosphere with great accuracy and stable calibration (Eplee Jr et al., 2011). Hsu et al. (2006) established deep blue (DB) aerosol retrieval algorithm for SeaWiFS over land. SeaWiFS makes its AOD more reliable because of its high calibration and long term data range. Monthly AOD (SWDB-L2) product available from September 2002 to May 2017 over south Asia was acquired from (http://giovanni.gsfc.nasa.gov.).

\subsubsection{Meteorological datasets}

The datasets of meteorological parameters (relative humidity $(\mathrm{RH})$, temperature (TEMP) and wind speed (WS)) have been obtained from (http://giovanni.gsfc.nasa.gov.). To understand the association of AOD with meteorological parameters and EVI, monthly average datasets of WS, TEMP, RH and EVI are used from September 2002 to December 2020 over South Asia.

\section{Results And Discussions}

\subsection{Validation of Aqua-AOD with Terra, MISR and SeaWiFS observations.}

Recent studies have validated MODIS-AOD with SeaWiFS AOD and MISR AOD to acquire accuracy in the measurement of remote sensing data (Tariq et al., 2018). Figure 3 exhibits the comparison of monthly data of Aqua-AOD at the wavelength of 550nm with observations of Terra-AOD, SeaWiFS and MISR-AOD from 2002 to 2020 over the study region. The highest correlation of 0.97 is obtained between Aqua and Terra AOD due to the same aerosol retrieval algorithm for both sensors. The value of the $y$-intercept is 0.03 and the slope is 1.11 respectively. A correlation coefficient $(R)$ of 0.93 is obtained among MISR and Aqua-AOD. The slope value of 0.97 and y-intercept of 0.01 exhibits that the MISR satellite data underestimate AOD observations as compared to Aqua. Martonchik et al. (1998) reported that the different aerosol retrieval algorithm and wavelength of MISR and Aqua-MODIS cause this underestimation. The lowest R-value of 0.58 is obtained among Aqua and SeaWiFS AOD. The slope value of 0.85 and $y$-intercept of 0.07 represent the underestimation of SeaWiFS AOD. This underestimation of AOD is due to the calibration of instruments (Remer et al., 2005). 


\subsection{Spatial distribution of AOD}

Figure 4 represents the distributions of annual mean Aqua-AOD over south Asia during the period September 2002-December 2020. The mean annual AOD values (0-1) retrieved from Aqua-MODIS show significant spatial variability over south Asia. The findings from Figure 4 shows that AOD had a marked impact on countries in South Asia, namely Afghanistan, Nepal, Maldives, Bhutan, Sri Lanka, India, Bangladesh and Pakistan. This study includes South Asian countries due to their geographic locations, vehicular and industrial emissions. High AOD ( 0.7) is observed over eastern Pakistan while AOD $₫ 0.6$ exists over southeastern Pakistan due to anthropogenic emissions. This includes an industrial area of Lahore, Gujranwala, Sialkot, Faisalabad, Jacobabad, Larkana, Hyderabad, Nawabshah and Karachi. Sharif et al. (2015) also reported high AOD over the southeastern region of Pakistan. The highest mean annual AOD ( $\mathbb{0} .7)$ has been observed over the IGB region. Recent studies have reported that high AOD over the IGB region is due to the increased industrialization, burning of crop residue, high population density, burning of biomass, heavy urbanization and burning of coal (Jethva et al., 2005; ul-Haq et al. 2016). In addition, low population areas in this study region also contribute to aerosol emissions from garbage and wood burning. Low AOD values ( $\mathbb{0} .3$ ) are observed over the northwestern region of Pakistan due to less population and reduced agricultural activity. Mean annual AOD values of $₫ 0.3$ are observed consistently over a wide area of India. In previous studies (Washington et al., 2003), the dominance of heavy aerosol loading over the northern region and IGP of India is observed in Figure 4. Similar to the outcomes acquired by Nizar and Dodamani, (2019), a significant decline in aerosol loading is seen over the Himalayas and Tibetan Plateau as compared to the IGB. Srivastava et al. (2016) reported aerosol loading over the west coast adjoining areas of India. Thus, aerosol loading over ocean regions is due to continental aerosols and marine traffic.

Figure 5 represents the seasonal distribution of averaged Aqua-AOD at a wavelength of $550 \mathrm{~nm}$ over south Asia from 2002 to 2020 . The seasonality of AOD, despite some variations observed from area-toarea, in general, demonstrates lower AOD observed during pre-monsoon and winter season while higher AOD was seen during the period of post-monsoon and monsoon, depending upon the area. During the winter season, the highest AOD (0.8) is observed over the Bihar state of India as shown in Figure 5a. The

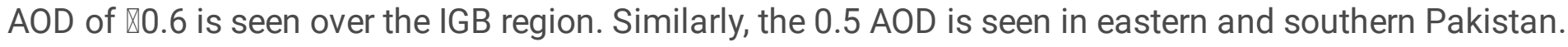
In agreement with the findings by Tariq and Ali. (2015), higher values of AOD have been observed over the southern region of Pakistan and the main sources of aerosols loading over the region includes desert aerosols transported from Cholistan and Thar deserts. It is evident from Figure 2a that the areas of northwestern and southwestern Pakistan show the minimum AOD of $₫ 0.2$. IGB is often surrounded by haze activity during the winter season which resulted in heavy aerosol loading over the region (Badrinath et al., 2009). In the pre-monsoon, the highest AOD value of $₫ 0.6$ is seen over the IGB region as shown in Figure $2 \mathrm{~b}$. The $0.5 \mathrm{AOD}$ is also detected in the eastern region of Pakistan and $₫ 0.3$ is seen over central India. Figure $2 \mathrm{~b}$ displays that the lowest AOD of 0.2 is observed in northwestern Pakistan.

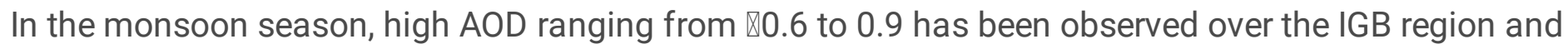
eastern Pakistan. The high AOD during monsoon over IGB and eastern region of Pakistan are due to 
biomass burning and emissions from vehicles. The $0.8 \mathrm{AOD}$ value is also observed in the southeastern region of Pakistan. Similarly, the $₫ 0.6$ AOD value is noticed in the eastern region of India and the southwestern region of Pakistan. It is evident from Figure $5 c$ that the minimum AOD of $\llbracket 0.3$ is seen in northwestern Pakistan and the southern region of India. In the post-monsoon season, the $\triangle 0.7$ AOD value is detected over few areas of the IGB region as shown in Figure $4 \mathrm{~d}$. The $\sim 0.5$ AOD value is noticed in central India. Similarly, the $\triangle 0.3$ AOD value is observed in the southwestern region of Pakistan. Finally, it is noticed from Figure $2 d$ that the northern region of Pakistan shows a minimum AOD of 0.2. Chung et al. (2005) analyzed that anthropogenic aerosols contribute about 70\% to the overall AOD over south Asia.

Seasonal distributions of AOD anomalies over south Asia from 2002 to 2020 are shown in Figure 6. During the winter season, a high anomaly value of 0.2 is observed over few areas of eastern Pakistan and western India as shown in Figure 6a. Major sources of high AOD anomaly values over these regions are due to excessive crop residue burning, urbanization and industrialization. In all the seasons, regions with low AOD anomaly values were situated in less-developed and rural regions of southwestern and northeastern Pakistan. In the pre-monsoon season, the anomaly of 0.1 is seen over the IGB region and eastern Pakistan. The most noticeable feature is that (only during monsoon) negative AOD anomaly values were seen over southeastern and eastern Pakistan and eastern India. The positive AOD anomaly values were dominated in western and southern parts of Pakistan and India respectively as shown in Figure 6c. In terms of the magnitude of AOD anomalies and area coverage, it is worth presenting that positive AOD anomaly centers were observed during winter, followed by post-monsoon, pre-monsoon, and least being monsoon. In post-monsoon, the highest AOD anomaly is observed over southeastern Pakistan and western areas of India as shown in Figure $6 \mathrm{~d}$.

Figure 7 represents spatial correlation maps of AOD with meteorological variables (TEMP, RH and WS) and MODIS-Aqua retrieved (EVI) over south Asia during the period September 2002-December 2020. A

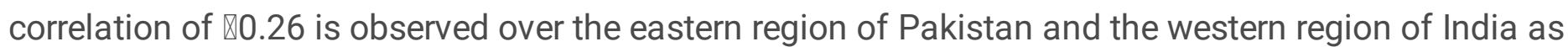
shown in Figure 7a. The highest positive correlation of $₫ 0.54$ is obtained among AOD and RH over the northeastern region of Pakistan and the central part of India while a negative correlation is observed over a southwestern region of Pakistan as shown in Figure 7b. Xueliang et al. (2012) reported that meteorological variables such as pressure, WS, RH, TEMP and wind direction change the chemical composition and path of aerosols. The increase in $\mathrm{RH}$ values on the western side of the Indian region accompanied by a decline in $\mathrm{RH}$ over eastern regions of India. The highest correlation among AOD and WS is observed over the southeastern region of Pakistan and the eastern region of India. The maximum negative correlation of -0.58 is observed among the AOD and EVI over the western region of India as shown in Figure $7 \mathrm{~d}$. The negative correlation shows that an increase (decrease) in AOD results in a decrease (increase) in EVI over the area. In northeastern and southeastern Pakistan, a negative R ( -0.3) among the AOD and EVI is seen due to the presence of high aerosols loading and low EVI. Tariq et al. (2021) also indicated a negative correlation among AOD and EVI over Lahore, Multan, Faisalabad, Jacobabad and Karachi. The highest positive R of 0.54 is observed over Madhya Pradesh and Maharashtra, India. 


\subsection{Temporal variations in AOD}

Figure 8 exhibits the time series of monthly Aqua-AOD spatially averaged over the study region during the period September 2002- December 2020. The highest AOD (0.58) is found in June 2018 while the lowest AOD (0.17) is observed in December 2005. Anthropogenic emissions due to rapid urbanization, more fuel consumption and biomass burning are responsible for high aerosol loadings over south Asia. Prasad et al. (2007) reported high AOD over the IGB region in the summer as compared to other seasons. The slope value of 0.0002 represents an increasing trend of monthly mean AOD and the y-intercept is found to be 0.29. Ali et al. (2014) investigated aerosol loading over Lahore and obtained high AOD in the summer season due to high temperatures and dust activity.

Figure 9 demonstrate the monthly average AOD and their standard deviations over the study area from 2002 to 2020 . The highest AOD ( 0.44) is detected in June while the second-highest AOD ( 0.43) is seen in July. The minimum AOD ( 0.22) is obtained in December. The relative change between January and June AOD is $\sim 76 \%$. This depicts the impact of the high temperature during the summer months over the study region. The interannual variability of AOD is higher in the summer season than in winter as noticeable from the standard deviation of AOD as shown in Figure 9. Tariq et al. (2021) also reported high AOD over Pakistan in summer as compared to the winter season.

Table 1. Descriptive statistics of AOD over south Asian countries from September 2002 to December 2020.

\begin{tabular}{|llll|}
\hline Countries & Mean AOD & Maximum AOD & Minimum AOD \\
\hline Pakistan & $0.34 \pm 0.16$ & 0.66 & 0.02 \\
\hline India & $0.36 \pm 0.13$ & 0.72 & 0.08 \\
\hline Bangladesh & $0.45 \pm 0.11$ & 0.57 & 0.26 \\
\hline Nepal & $0.25 \pm 0.15$ & 0.55 & 0.02 \\
\hline Bhutan & $0.06 \pm 0.006$ & 0.07 & 0.05 \\
\hline Sri Lanka & $0.27 \pm 0.03$ & 0.33 & 0.24 \\
\hline Afghanistan & $0.20 \pm 0.08$ & 0.39 & 0.06 \\
\hline
\end{tabular}

The Aqua-AOD measured at $550 \mathrm{~nm}$ ranging from 0.02 to 0.66 with a mean value of $0.34 \pm 0.16$ over Pakistan, 0.08 to 0.72 with a mean of $0.36 \pm 0.13$ over India, 0.26 to 0.57 with a mean of $0.45 \pm 0.11$ over Bangladesh, 0.02 to 0.55 with mean of $0.25 \pm 0.15$ over Nepal, 0.05 to 0.07 with mean of $0.06 \pm 0.006$ over Bhutan and 0.24 to 0.33 with mean of $0.27 \pm 0.03$ over Sir-Lanka as shown in Table 1 . The descriptive statistics show that the aerosol loading was relatively higher over Pakistan, India and Bangladesh than Nepal, Afghanistan, Bhutan and Sri-Lanka. 
Figure 10 depicts the time series of MODIS-Aqua retrieved AOD over Kabul, Lahore, Karachi, New Delhi, Bangalore, Varanasi, Kathmandu and Dhaka from September 2002 to December 2020. The slope value of -2E-06 depicts the decreasing trend of AOD over Kabul with an intercept value of 0.5915 as shown in figure 10a. The highest AOD of $~ 0.28$ over Kabul was observed in March 2012. Figure 10b shows the increasing trend of Aqua-AOD over Lahore with a slope of 2E-05 and intercept of 0.5915 while the highest AOD of $\sim 1.36$ was observed in November 2014. The slope value of 5E-06 represents an increasing trend of AOD over Karachi as shown in Figure10c. The highest AOD of $\sim 1.0$ over Karachi was observed in August 2010. In New Delhi, the positive slope value of 0.0006 shows the increasing trend of AOD while the highest AOD ( 1.4) was observed in July 2019. Figure 10d shows slightly high AOD over New Delhi throughout the study period due to the high aerosol loading over the city from the IGB region. This increase in AOD affects the climate of New Delhi badly for the last few years. Panda et al. (2009) found increasing trends of AOD over New Delhi during the pre-monsoon and winter because of dust activity and burning of biomass.

The highest AOD of $~ 0.51$ over Bangalore was observed in May 2018 as shown in Figure 10e. The slope value of $3 \mathrm{E}-05$ and intercept of 0.119 represents rising trend of AOD over Bangalore. Ramachandran et al. (2012) found an increasing trend of AOD over Hyderabad and Bangalore due to the rapid increase in urbanization. Figure $10 \mathrm{f}$ shows the increasing trend of AOD over Varanasi, India. The slope and $y-$ intercept were 4E-05 and 0.4788 respectively while the maximum AOD of $\sim 1.5$ was observed in December 2019. The positive slope value of $2 \mathrm{E}-05$ depicts rising trend of AOD over Katmandu with a maximum AOD of 1.1 in June 2018 as shown in Figure 10g. Previous studies showed that the katabatic winds and topography of Katmandu cause pollutants to be trapped under inversion layers near the valley (Panday and Prinn, 2009). Figure 10h shows the increasing trend of AOD over Dhaka with the highest AOD of $\sim 1.2$ in June 2018. The y-intercept and slope from the linear model are 0.4204 and $4 \mathrm{E}-05$ respectively.

\section{Conclusion}

This study shows the spatiotemporal distribution of AOD and its association with EVI and meteorological variables from September 2002 to December 2020 over south Asia. The MODIS-Aqua AOD has been validated with datasets obtained from Terra, SeaWiFS and MISR to attain accuracy in the measurement of AOD. We find significant correlations of Aqua-AOD with Terra-AOD $(R=0.97)$, MISR-AOD $(R=0.93)$ and

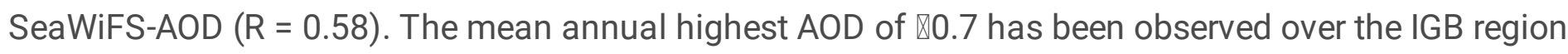
due to an increase in economical and agricultural activities. Apart from the IGB region, a remarkable

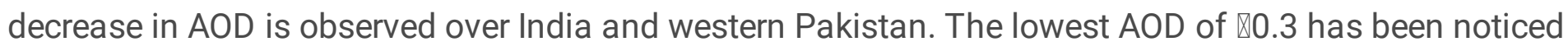
over northwestern Pakistan. The IGB region is characterized by peak AOD values during monsoon, premonsoon and post-monsoon. During winter, the highest AOD (0.8) has been seen over the Bihar state of India while the lowest AOD ( $\triangle 0.2)$ is seen over northwestern and southwestern Pakistan. High AOD (0.8) is observed in the southeastern region of Pakistan during the monsoon season. The highest anomaly value of 0.2 is observed over eastern Pakistan and western India. In eastern Pakistan and western India, AOD is

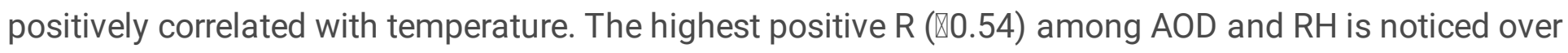
northeastern Pakistan and central India. The negative correlation of AOD and RH is seen over 
southwestern Pakistan. The AOD is negatively correlated ( -0.3) with EVI over northeastern and southeastern Pakistan while positively correlated $(R=0.54)$ over Madhya Pradesh and Maharashtra in India. The interannual variations of AOD display that the maximum AOD was found to be 0.58 in June 2018 while the minimum AOD of 0.17 was observed in December 2005. The intraannual changes in AOD show that the maximum AOD was found to be $\sim 0.44$ in June while the minimum AOD of $\sim 0.22$ was obtained in December. The highest mean AOD ( 1.5) is observed in Varanasi during September 2002December 2020.

\section{Declarations}

\section{Data Availability}

Data used in this study can be downloaded from the Giovanni website (http://giovanni.gsfc.nasa.gov).

\section{Acknowledgement}

We acknowledged NASA for providing us MODIS, MISR and SeaWiFS datasets and NOAA NCEP/NCAR Reanalysis group for meteorological datasets.

\section{Ethical Approval}

Not required

\section{Consent to Publish}

Not Applicable

\section{Consent to Participate}

All authors participate in this research.

\section{Authors Contributions}

Salman Tariq conceptualizes the work and wrote the manuscript. Fazzal Qayyum make maps and wrote the description. Usman Mehmood conducted analysis. Zia ul-Haq wrote the manuscript.

\section{Funding}

This work does not get any funding from any organization.

\section{Competing Interests}

Not Required

\section{Availability of data and materials}

Not required 


\section{References}

1. Alam, K., Khan, R., Sorooshian, A., Blaschke, T., Bibi, S., and Bibi, H. (2018). Analysis of aerosol optical properties due to Haze episode in the Himalayan foothills: Implications for climate forcing. Aerosol and Air quality Research, 18(5), 1331-1350.

2. Ali, M., Tariq, S., Mahmood, K., Daud, A., Batool, A., Ul-Haq, Z. (2014). A study of aerosol properties over Lahore (Pakistan) by using AERONET data. Asia-Pacific Journal of Atmospheric Science 50: 153-162.

3. Badarinath KVS, Kharol SK, Sharma AR, Roy PS (2009). Fog over Indo-Gangetic Plains-A study using multi-satellite data and ground observations. IEEE J. Selec. Topics Appl. Earth Obs. Remote Sens. 2(3): 185-195, doi:10.1109/JSTARS.2009.2019830.

4. Chung, C. E., Ramanathan, V., Kim, D., and Podgorny, I. A. (2005). Global anthropogenic aerosol25 direct forcing derived from satellite and ground-based observations, J. Geophys. Res., 110, D24207, doi: 10.1029/2005JD006356, 2005.

5. Eplee Jr., R. E., Meister, G., Patt, F. S., Franz, B. A., McClain, C. R. (2011). Uncertainty Assessment of the SeaWiFS On-Orbit Calibration. In: Butler, J. J., Xiong, X., Gu, X. (eds). Earth Observing Systems, Vol. 8153. Proc. SPIE 8153. DOI: 10.1117/12.892340.

6. Guo, J.-P.; Zhang, X.-Y.; Wu, Y.-R.; Zhaxi, Y.; Che, H.-Z.; La, B.; Wang, W.; Li, X.-W, (2011). Spatiotemporal variation trends of satellite-based aerosol optical depth in China during 1980-2008. Atmos. Environ. 2011, 45, 6802-6811.

7. Han, X., M. G. Zhang, J. H. Tao, et al., (2013). Modeling aerosol impacts on atmospheric visibility in Beijing with RAMS- CMAQ. Atmos. Environ., 72, 177-191, doi: 10.1016/j.at- mosenv.2013.02.030.

8. Hsu, N. C., Tsay, S. C., King, M. D., Herman, J. R. (2006). Deep blue retrievals of Asian aerosol properties during ACE-Asia. IEEE Transactions on Geoscience and Remote Sensing 44: 3180-3195.

9. Jethva, H., Satheesh, S. K., and Srinivasan, J. (2005). Seasonal variability of aerosols over the IndoGangetic basin, J. Geophys. Res., 110, D21204, doi: 10.1029/2005JD005938, 2005.

10. Kahn, R. A., Gaitley, B. J., Garay, M. J., Diner, D. J., Eck, T. F., Smirnov, A., Holben, B. N. (2010): Multiangle imaging spectroradiometer global aerosol product assessment by comparison with the aerosol robotic network. - Journal of Geophysical Research 115(D23). http://dx.doi.org/10.1029/2010JD014601.

11. Logan, T.; Xi, B.; Dong, X.; Li, Z.; Cribb, M (2013). Classification and investigation of Asian aerosol absorptive properties. Atmos. Chem. Phys. 2013, 13, 2253-2265.

12. Martonchik, J. V., Diner, D. J., Kahn, R. A., Ackerman, T. P., Verstraete, M. M., Pinty, B., Gordon, H. R. (1998). Techniques for the retrieval of aerosol properties over land and ocean using multi-angle imaging, - IEEE Transactions on Geoscience and Remote sensing 36: 1212-1227.

13. Nichol, J.; Bilal, M (2016). Validation of MODIS $3 \mathrm{~km}$ resolution aerosol optical depth retrievals over Asia. Remote Sens. 2016, 8, 328. 
14. Nizar, S and Dodamani, BM (2019). Spatiotemporal distribution of aerosols over the Indian subcontinent and its dependence on prevailing meteorological conditions. Air Quality, Atmosphere \& Health (2019) 12:503-517 https://doi.org/10.1007/s11869-019-00677.

15. Panda J, Sharan M, Gopalakrishnan, SG (2009). Study of regional-scale boundary layer characteristics over northern India with a special reference to the role of the Thar Desert in regionalscale transport. J. Appl. Meteorology Climatology 48(11):2377-2402.

16. Panday, A.K., Prinn, R.G., (2009). Diurnal cycle of air pollution in the Kathmandu Valley, Nepal: Observations. J. Geophys. Res. 114, D09305. https://doi.org/10.1029/2008JD009777 .

17. Prasad AK and Singh RP (2007). Changes in aerosol parameters during major dust storm events (2001-2005) over the Indo-Gangetic Plains using AERONET and MODIS data. J. Geophys. Res. 112: D09208, doi: 10.1029/2006JD007778.

18. Prasad, A. K., Singh, S., Chauhan, S. S., Srivastava, M. K., Singh, R. P., Singh, R. (2007): Aerosol radiative forcing over the Indo-Gangetic plains during major dust storms. - Atmospheric Environment 41: 6289-6301.

19. Remer, L. A., Y. J. Kaufman, D. Tanré, S. Mattoo, D. A. Chu, J. V. Martins, and R. R. Li. et al. (2005). "The MODIS Aerosol Algorithm, Products, and Validation." Journal of the Atmospheric Sciences 62 (4): 947-973. doi:10.1175/jas3385.1.

20. Sharif, Fozia \& Afsar, Sheeba. (2015). Spatio-temporal distribution of aerosol and cloud properties over Sindh using MODIS satellite data and a HYSPLIT model. Aerosol and Air Quality Research. 15. 657-672.

21. Srivastava N, Satheesh SK, BlondN, Moorthy KK (2016). Anthropogenic aerosol fraction over the Indian region: model simulations versus multi-satellite data analysis. Int J Remote Sens 37:782804. https://doi.org/10.1080/01431161.2015.1136445.

22. Streets DG, Yan F, Chin M, Diehl T, Mahowald N, Schultz M, Wild M, Wu Y, Yu C (2009) . Anthropogenic and natural contributions to regional trends in aerosol optical depth, 1986-2006. J Geophys Res 114:D00D18. doi:10.1029/2008JD011624.

23. S., Ramachandran \& Kedia, Sumita \& Srivastava, Rohit. (2012). Aerosol optical depth trends over different regions of India. Atmospheric Environment. 49. 10.1016/j.atmosenv.2011.11.017.

24. Tariq, S., ul-Haq, Z., Ali, M. (2015). Analysis of optical and physical properties of aerosols during crop residue burning event of October 2010 over Lahore, Pakistan. Atmospheric Pollution Research 6: 969978.

25. Tariq, S and Ali, M (2015). Spatio-temporal Distribution of Absorbing Aerosols over Pakistan Retrieved from OMI Onboard Aura Satellite. Atmospheric Pollution Research, Volume 6, Issue 2 (March 2015), Pages 254-266, doi: 10.5094/APR.2015.030.

26. Tariq, S., Ul-Haq, Z., Mahmood, K., Asim, DR. (2018). Spatio-temporal distributions and trends of aerosol parameters over Pakistan using remote sensing. Applied Ecology and Environmental Research 16(3):2615-2637. 
27. Tariq, S., Nawaz, H., ul-Haq, Z., Mehmood, U., Investigating the relationshipof aerosols with enhanced vegetation index and meteorological parameters over Pakistan, Atmospheric Pollution Research (2021), doi: https://doi.org/10.1016/j.apr.2021.101080.

28. ul-Haq, Z., Tariq, S., Ali, M. (2016). Spatiotemporal patterns of correlation between atmospheric nitrogen dioxide and aerosols over South Asia. Meteorology and Atmospheric Physics 129(5): 507527. DOI: 10.1007/s00703-016-0485-6.

29. Washington R, Todd M, Middleton NJ, Goudie AS (2003). Dust storm source areas determined by the Total Ozone Monitoring Spectrometer and surface observations. Ann. Assoc. Am. Geogr. 93: 297313.

30. Xueliang D, Chune S, Biwen W, Zhenghua C, Suping N, Dongyan H, Hao Z (2012) Analysis of aerosol characteristics and their relationships with meteorological parameters over Anhui province in China. Atmos Res 109-110:52-63

\section{Figures}




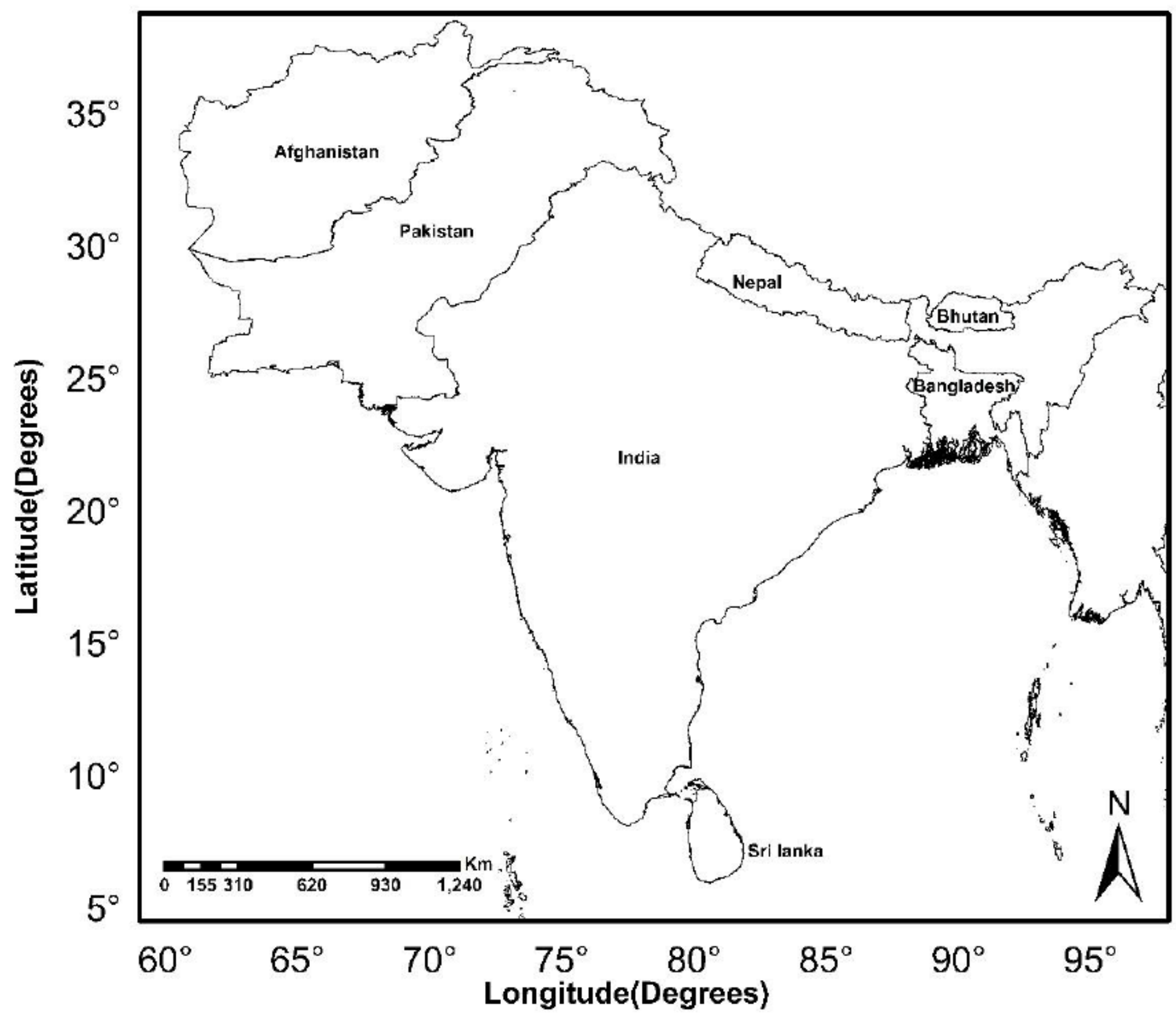

Figure 1

Study area representing countries of south Asia 

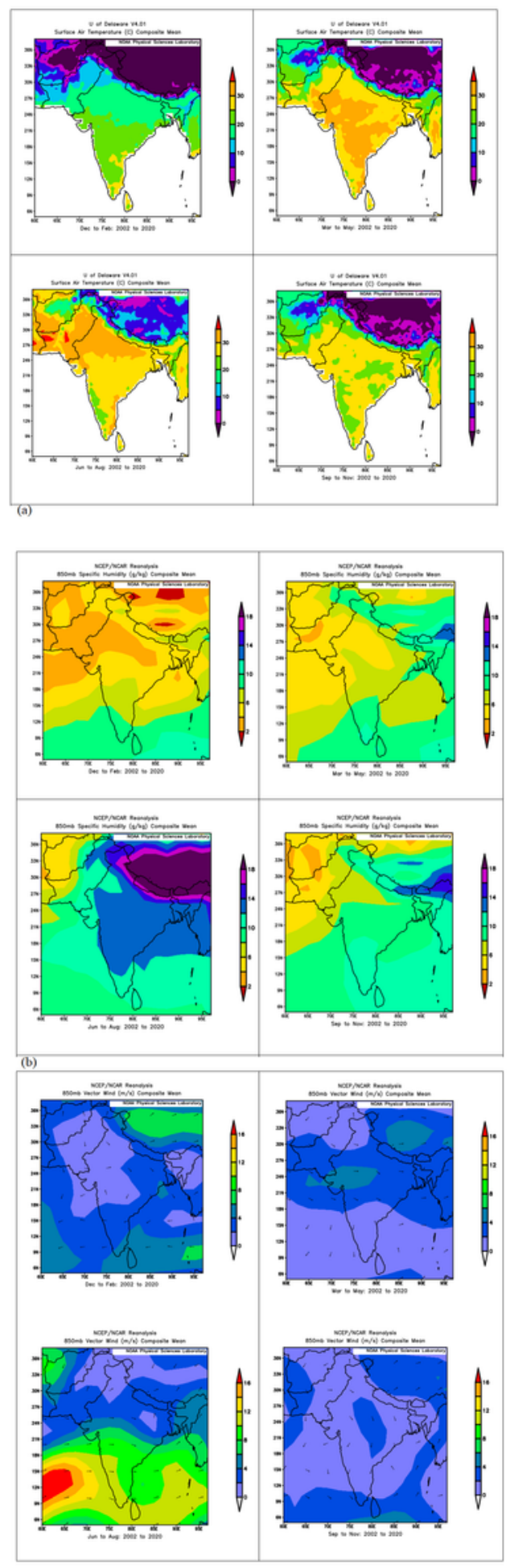

(c)

\section{Figure 2}

Maps of meteorological variables ((a) surface air (b) specific humidity and (c) wind speed) during four main seasons DJF (December-February), MAM (March-May), JJA (June-August) and SON (SeptemberNovember) of 2002 to 2020 obtained from NCEP-Reanalysis, NOAA/ESRL physical science division, over south Asia during 2002-2020. Figure 2 exhibits the seasonal mean of meteorological variables (specific humidity, surface air and vector wind) over the study area during the time span of 2002 to 2020 using 
NCEP/NCAR reanalysis data. It can be seen from Figure $2 a$ that the eastern region of Pakistan have high surface air $\left(\sim 35 \mathrm{C}^{\circ}\right)$ while a wide region of India has $30 \mathrm{C}^{\circ}$ during the period June-August. Figure $2 \mathrm{~b}$ exhibits that the eastern and northeastern region of Pakistan have specific humidity of $15 \mathrm{~g} / \mathrm{kg}$ whereas the central Indian region has specific humidity of $14 \mathrm{~g} / \mathrm{kg}$ during the period June to August. In Figure 2c strong winds of $\sim 4 \mathrm{~m} / \mathrm{s}$ can be found over the southeastern region of Pakistan and of $\sim 10 \mathrm{~m} / \mathrm{s}$ over southern parts of India during the period June 2002-August 2020.
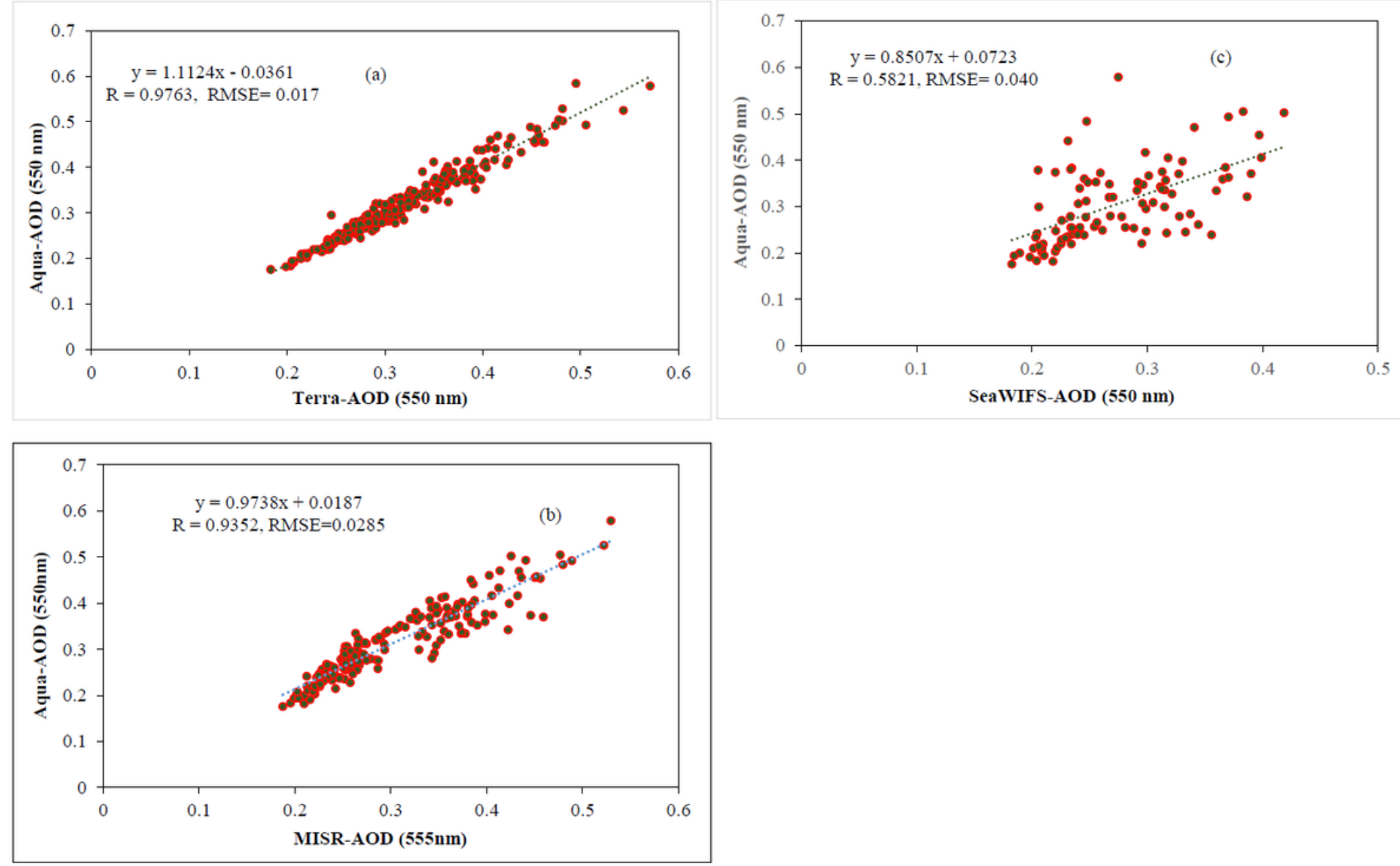

Figure 3

Validation of Aqua-AOD at $550 \mathrm{~nm}$ over land with (a) Terra-AOD at $550 \mathrm{~nm}$ over land, (b) MISR-AOD at 555 $\mathrm{nm}$ and (c) SeaWiFS-AOD at $550 \mathrm{~nm}$ over south Asia during the study period. 


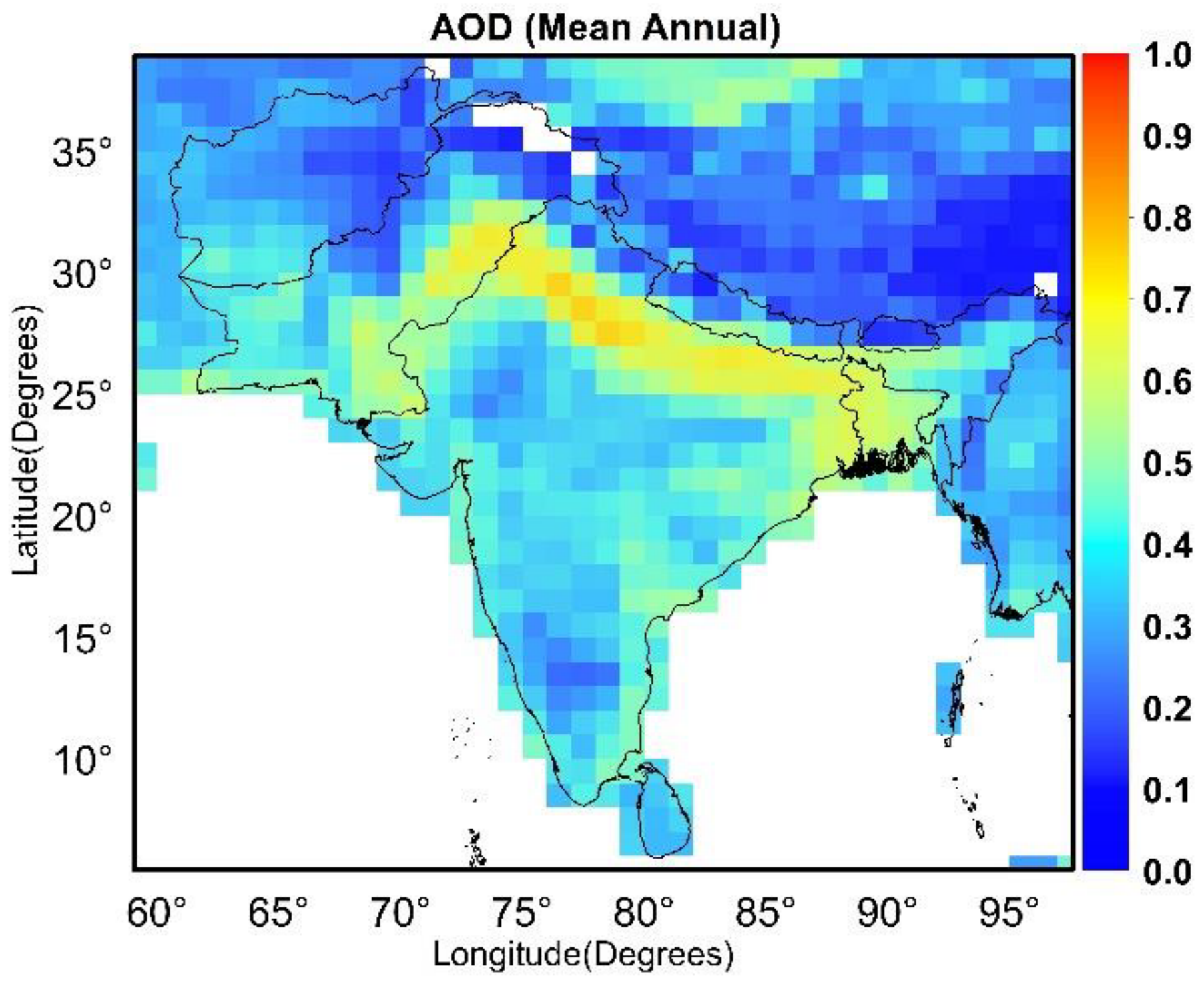

Figure 4

Spatial distribution of mean annual AOD over south Asia during September 2002-December 2020 and white area represents no data. 


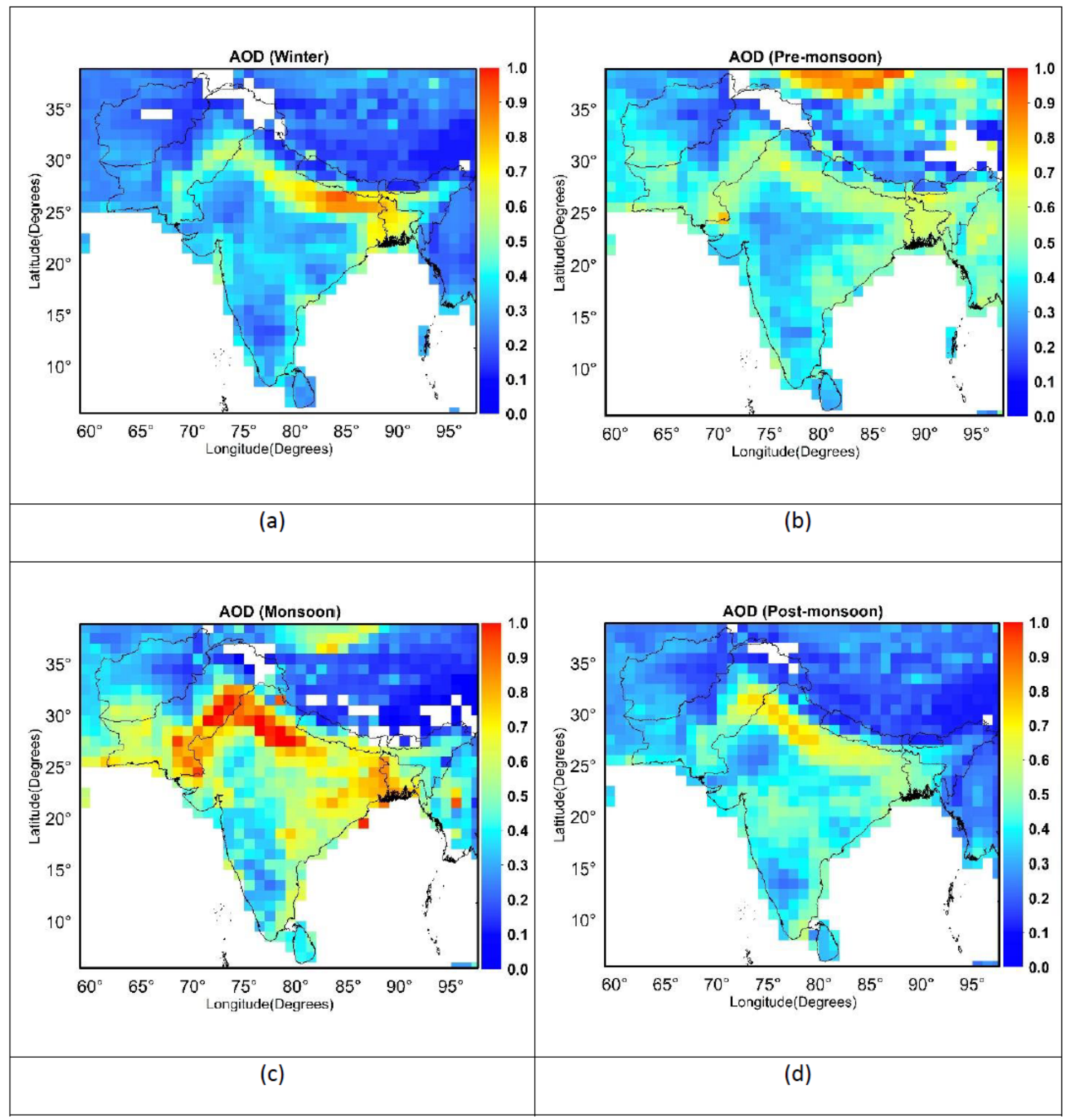

Figure 5

Spatial distribution of deep blue Aqua-AOD (550nm) during (a) winter, (b) pre-monsoon, (c) monsoon and (d) post-monsoon seasons over the study region during the period September 2002-December 2020. 


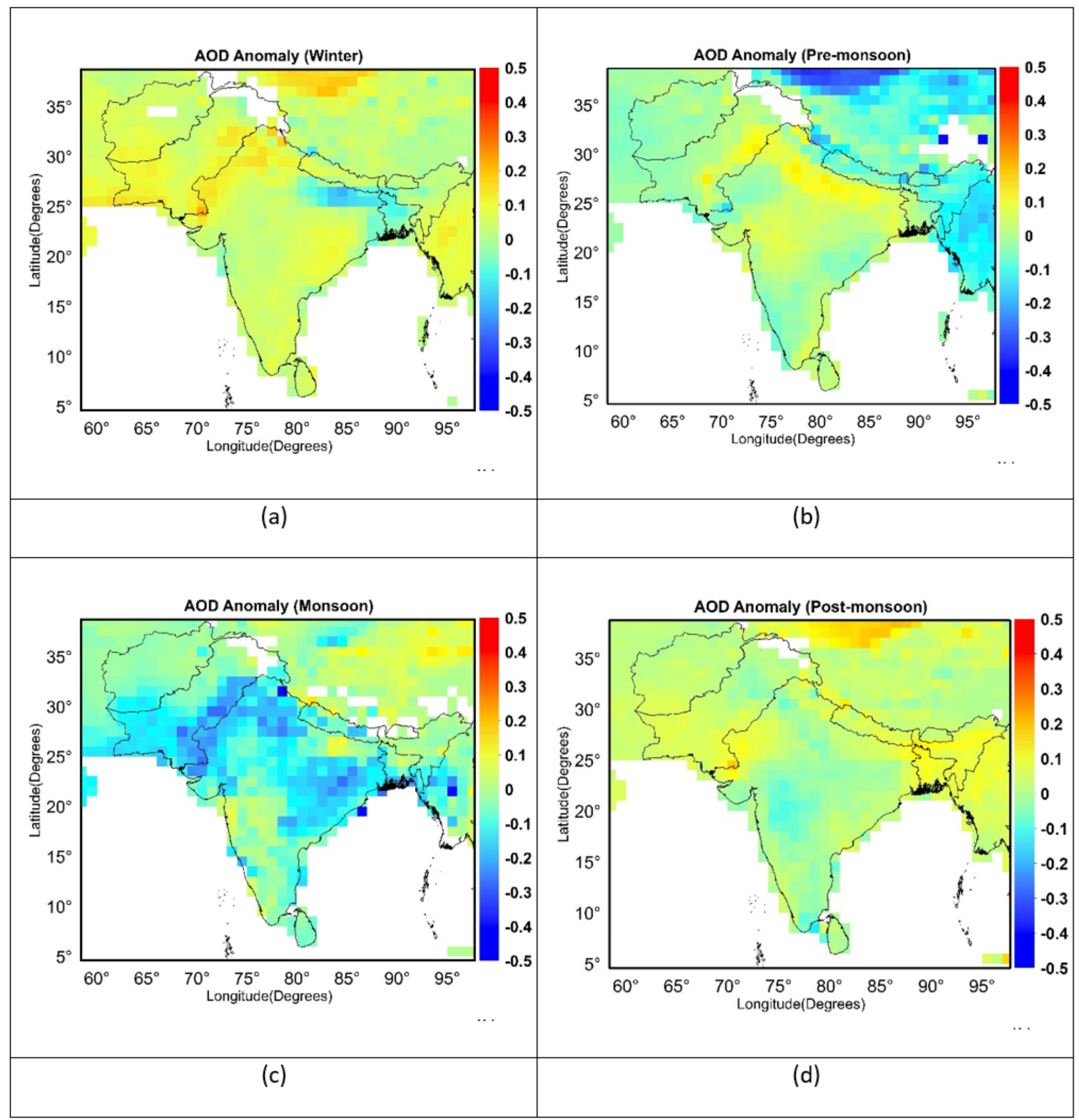

Figure 6

Spatial distribution of deep blue Aqua-AOD anomaly during (a) winter, (b) pre-monsoon, (c) monsoon and (d) post-monsoon period over the study region during the period September 2002-December 2020. 


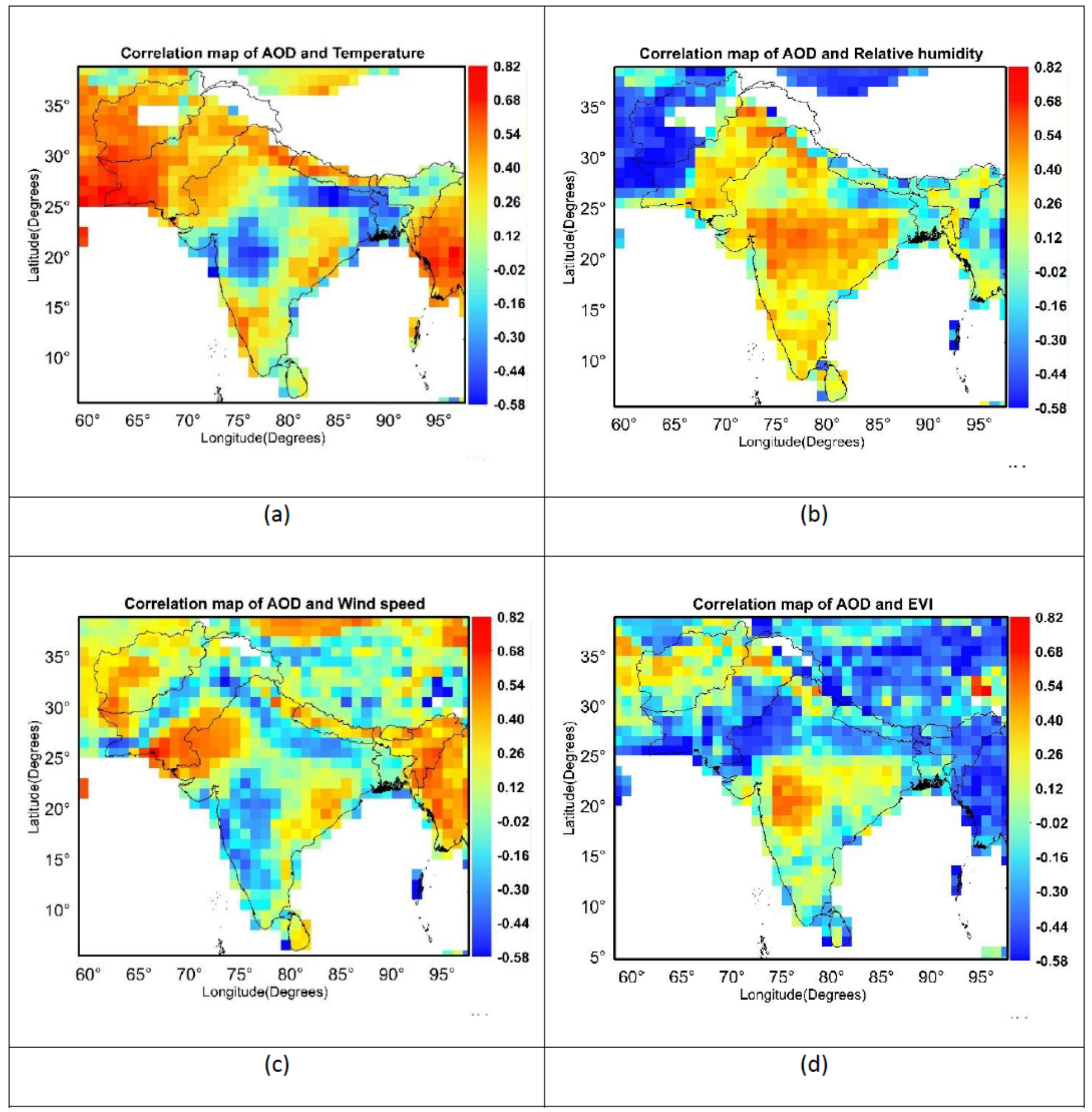

Figure 7

Spatial correlation maps between AOD and (a) TEMP (b) RH (c) WS and (d) EVI over south Asia from 2002 to 2020. 


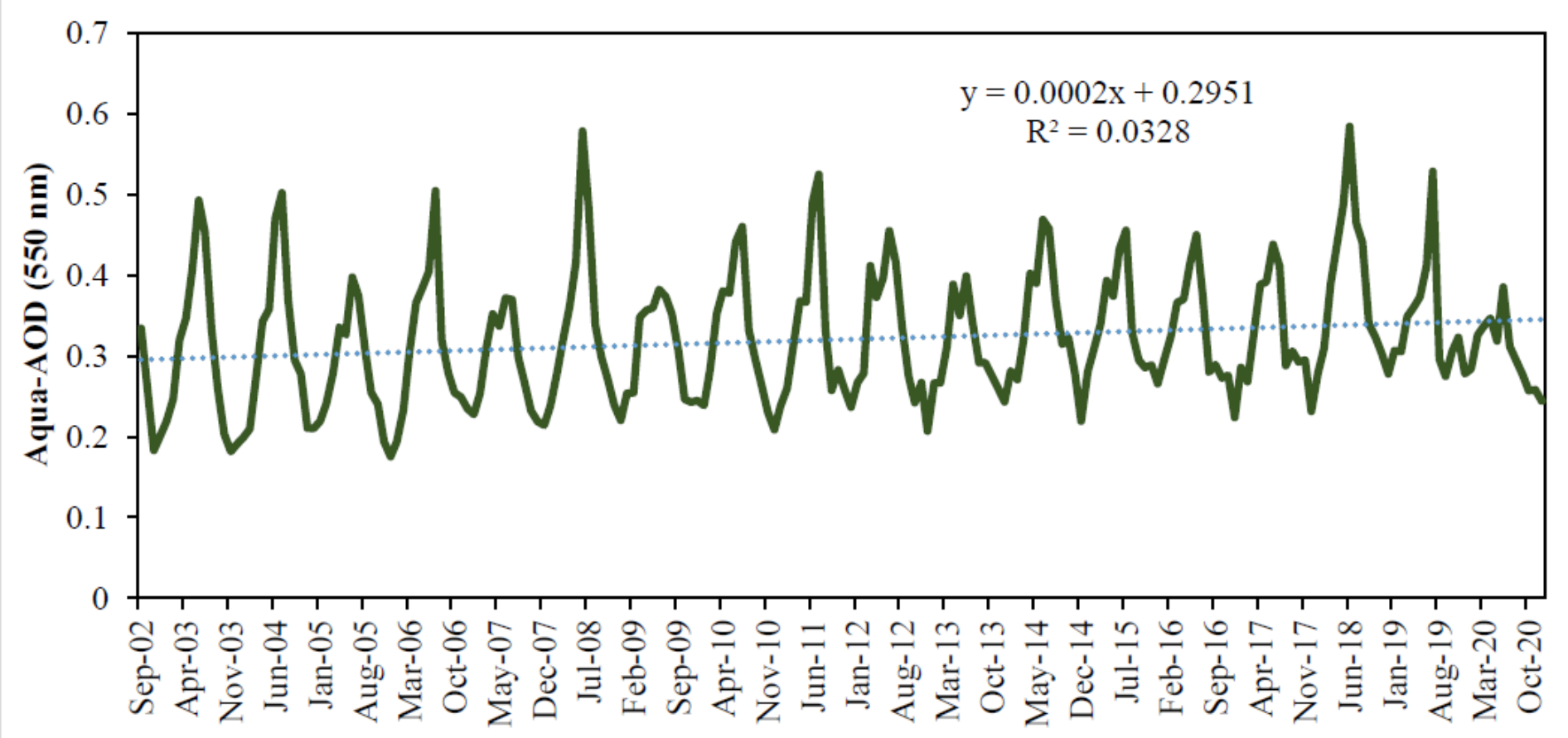

Figure 8

Time series of monthly Aqua-AOD over south Asia during the period of 2002-2020.

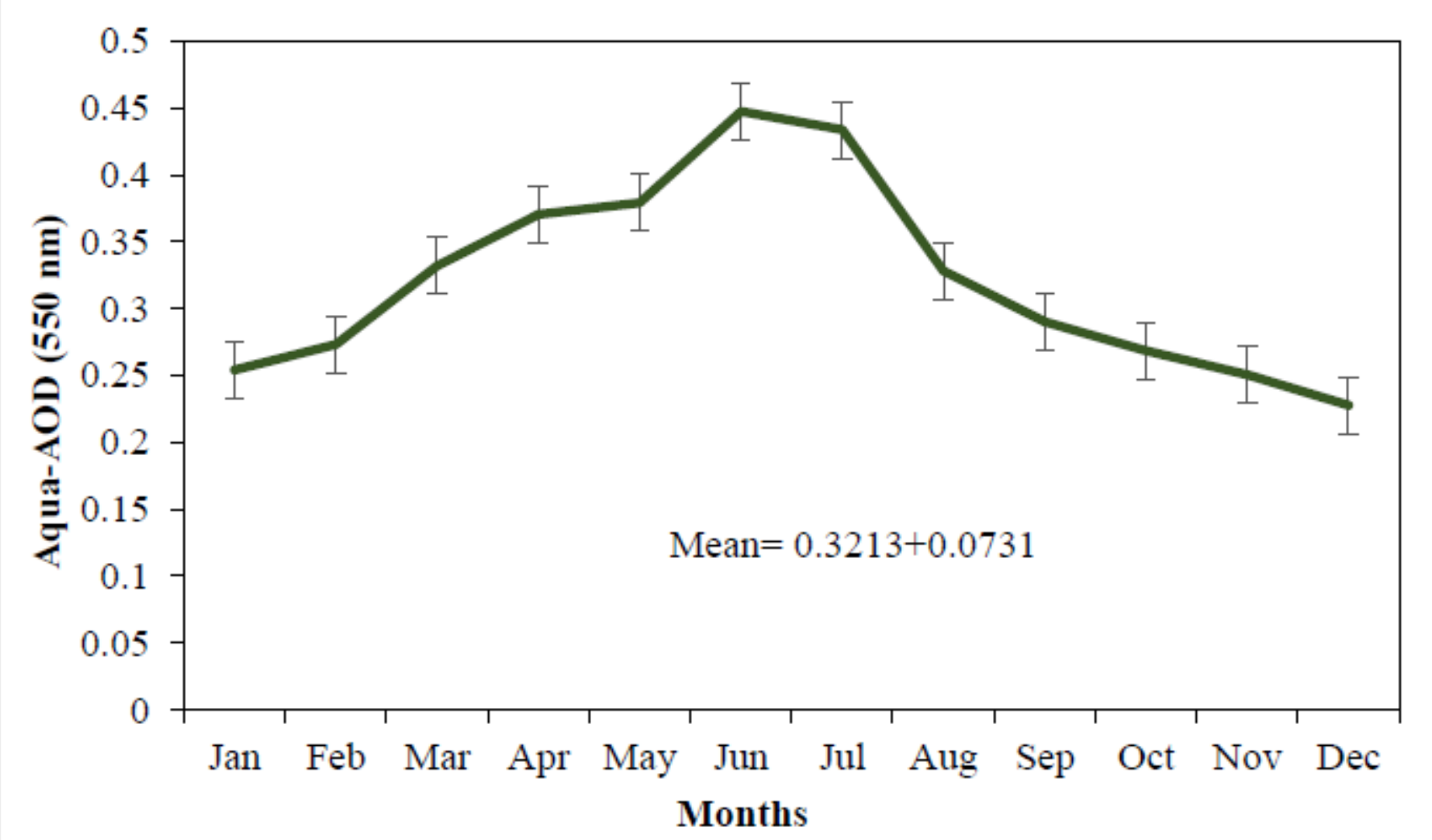

Figure 9 
Monthly average Aqua-AOD variations over south Asia during the period 2002-2020.
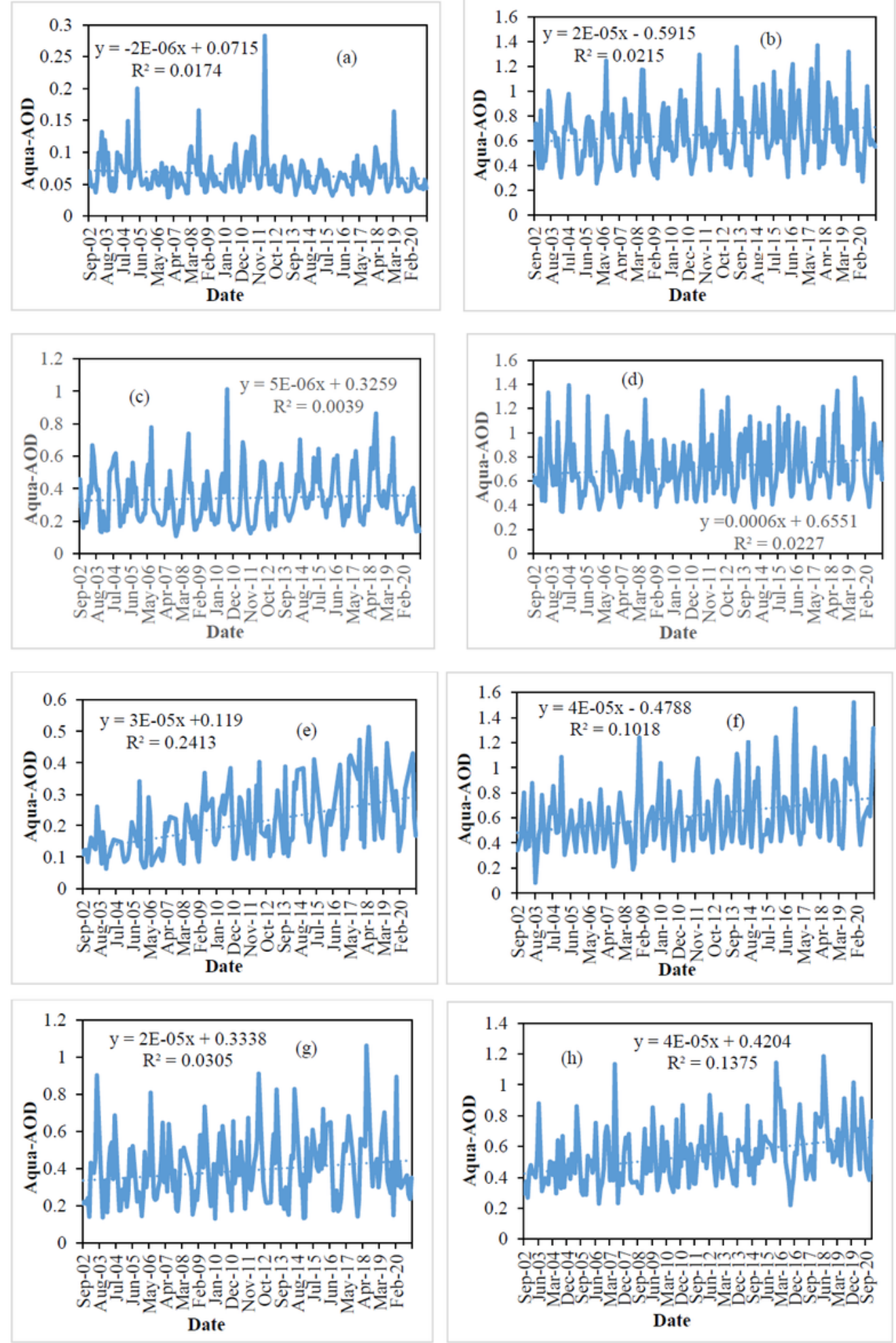

Figure 10

Time series of megacities of south Asia (a) Kabul, (b) Lahore,(c) Karachi,(d)New Delhi,(e) Bangalore,(f) Varanasi,(g) Kathmandu and (h) Dhaka. 